\title{
La Remolacha y Napoleón
}

\author{
The Beet and Napoleon
}

Ernesto Ponce López ${ }^{1}$

\section{RESUMEN}

Esta historia va dirigida a conocer el desarrollo de la producción del azúcar de remolacha y de su antecesora, la de caña, con las consecuencias generadas: sociales, históricas, culturales, económicas y geopolíticas. Durante siglos la caña de azúcar fue la fuente de obtención del endulzante más conocido de la historia. La pérdida de Haití en 1803, su principal colonia abastecedora de este producto, lleva a Napoleón a ofrecer un gran premio para quien proporcionase una solución al grave problema: suministro de azúcar a la Europa ocupada y a sus tropas conquistadoras. Quien propuso la mejor solución fue el empresario Benjamin Delessert, que desarrolló la producción del azúcar de remolacha, se le concedió la Legión de Honor y posteriormente Bonaparte le nombró barón del Imperio. Las consecuencias económicas pronto aparecieron: Alemania y otros países siguieron el ejemplo, la dependencia de los productores tropicales fue menor, porque los cultivos de remolacha, siendo de gran rendimiento, además son posibles en climas templados. Los negocios internacionales del azúcar estuvieron ligados con la Revolución Industrial. Se generaron conflictos, guerras e invasiones por el dominio del mercado. Actualmente la remolacha y otras plantas son una esperanza en la fabricación de biocombustibles para un mundo que los necesita.

Palabras clave: Remolacha, azúcar.

\section{ABSTRACT}

This story is intended to meet the development of beet sugar production and its predecessor, the cane sugar, with the consequences generated: historical, social, cultural, economic and geo-political. For centuries, sugar of cane was the source of production of the sweetener best known of the history. The loss of Haiti in 1803, its main colony supplier of this product, obliges Napoleon to offer a great prize for those who provide a solution to the serious problem: sugar supply of occupied Europe and his conquering troops. Who proposed the best solution was the businessman Benjamin Delessert, who developed the sugar beet production, was awarded the Legion of Honor and later Bonaparte appointed him Baron of the Empire. The economic consequences were soon appeared: Germany and other countries followed suit, dependence was lower from tropical producers because beet crops is of great performance, also are possible in temperate climates. International sugar business was linked with the Industrial Revolution. There were generated conflicts, wars and invasions for market dominance. Currently the beet and other plants, are a hope in the manufacture of bio-fuels for a world that needs them.

Key words: Beet, sugar.

\section{Introducción}

El azúcar, en sus distintas formas, muchas plantas lo tienen en la savia, en un período de su desarrollo, luego hay muchas fuentes naturales de azúcar. El término viene del árabe antiguo, sukkar. Hay plantas que almacenan azúcar para emplearla en otras estaciones, hay otras que almacenan y emplean almidón. Las frutas y algunas raíces tienen azúcar en gran cantidad: uvas, remolachas, zanahorias y los camotes, entre otros. Las raíces lo guardan para usarlo en el segundo año de desarrollo, allí les sirve para formar su tallo, hojas, flores y semillas. En los trópicos y países templados también producen azúcar las palmeras. En la Antigüedad se obtenía de la miel, que a su vez provenía de flores. La caña de azúcar, similar a un tallo de maíz pero sin su interior ahuecado, contiene un zumo dulce. Puede sembrarse en zonas húmedas de los trópicos. Siendo superior en calidad a las otras plantas productoras de azúcar. Hay referencias de la caña de azúcar desde hace unos 5.000 años. La ruta de la caña fue desde Oriente a Occidente, desde el océano Índico al mar Mediterráneo y de allí al Atlántico y Pacífico. Su origen fue en Nueva Guinea, llegando por mar a la India, desde donde se pasó a China y al Cercano Oriente. Los hindúes fueron los primeros en fabricar azúcar. Cerca de 510 A.C. la caña llega a Persia,

1 Escuela Universitaria de Ingeniería Mecánica. Universidad de Tarapacá. Arica. Chile. E-mail: eponce60@ gmail.com 
donde los súbditos del Rey Darío la llamaron como la caña que da miel.

Su llegada a Europa se produce en el siglo IV A.C. debido a la conquista del imperio persa por Alejandro el Grande. Los griegos la dejaron a los romanos, que la llamaron "sal de la India". Los árabes en el siglo VII D.C. al ocupar las regiones del Tigris y el Éufrates redescubren las grandes ventajas que tiene. Ellos la introducen en las zonas recientemente conquistadas, cultivando la caña en países como Siria, Egipto y el Norte de África. Luego los alquimistas egipcios mejoran su procesamiento. En Europa se conoce por los viajes de los venecianos y más tarde por las Cruzadas. A España llega en la Edad Media. Con la colonización de América, el azúcar va con los conquistadores a La Hispaniola (actual Santo Domingo) donde se cultiva a gran escala. Más tarde va a Cuba y México. Otros españoles la llevan en sus viajes a las Islas Filipinas y archipiélagos del Pacífico. Después los portugueses la plantan en Brasil y los franceses en sus colonias del Océano Índico, posteriormente los holandeses la llevan a las Antillas. Fue casi la única fuente comercial de azúcar hasta el siglo XIX. Hubo un malvado tráfico de esclavos provenientes de África y operaciones mercantiles donde intercambiaban ron por esclavos y éstos por la melaza para las fábricas de licor de las 13 colonias inglesas y luego para Estados Unidos. Terminando el siglo XVII se producía y consumía azúcar de caña en casi todo el mundo.

En 1705, el francés Olivier Serrés estudia y descubre las propiedades de la remolacha. Más tarde, el químico alemán Margraf desarrolla un proceso para extraer y solidificar el azúcar de esta raíz, propiciando la creación de las primeras industrias de azúcar en Prusia. A comienzos del siglo XIX las colonias americanas eran las más importantes productoras mundiales de azúcar de caña; su lucha independentista creó un serio problema para el abastecimiento europeo. Haití, el primer productor mundial, se independizó de Francia. Napoleón I ofreció un premio para quien proporcionase una solución al grave problema: suministro de azúcar a la Europa continental ocupada. Quien propuso la mejor solución fue el empresario Benjamin Delessert que desarrolló eficientemente la producción del azúcar de remolacha, se le concedió la Legión de Honor y posteriormente Bonaparte le nombró barón del Imperio. Esto forzó a Napoleón Bonaparte al fomento y difusión del cultivo de la remolacha, acompañadas de la construcción de refinerías en
Francia, seguido por otras naciones de Europa Central y Alemania. La difusión y necesidad de consumo ha terminado de ubicar al azúcar en un grupo de productos conectados a las fuerzas económicas, que modelaron al mundo actual. Este fenómeno permite la comprensión de los procesos que marcaron la Revolución Industrial y las relaciones económicas entre distintos países, aunque tuvo un elevado costo social (Espinoza, 1980).

\section{Inicio del conflicto}

A fines del siglo XVIII las mejores tropas de las colonias europeas estaban en la isla Hispaniola, actual Haití. Entrenados y mandados por oficiales franceses eran un ejército disciplinado de ex esclavos provenientes principalmente de Dahomey, famosos por su bravura. Bien entrenados, con una alta moral, era una fuerza temible. Ellos contenían a los ingleses de Trinidad, a los holandeses en sus posesiones, a los españoles de Cuba, Santo Domingo y otras regiones caribeñas. Cuando Francia apoyó a los norteamericanos en su independencia de Inglaterra, el mayor contingente de tropas coloniales enviadas por el gobierno francés provenía de Haití. Tuvieron una destacada participación en esa guerra, regresando triunfantes a su isla después de derrotar a tropas inglesas consideradas entre las mejores de Europa.

Haití era un país rico, que producía el $50 \%$ del azúcar comercializada en el mundo, además de cacao, ron y café. Sin embargo, había castas bien diferenciadas: a) los terratenientes, dueños de las plantaciones, de los complejos azucareros, del comercio con Europa y de la riqueza de la isla; b) los blancos menores, encargados de la administración y el comercio local; c) los mulatos y negros libres, teniendo los mulatos 32 niveles distintos de mezcla de sangre con diferentes nombres en cada nivel de color; d) los negros cimarrones, esclavos escapados de sus amos y que se ocultaban en las montañas de la isla; e) finalmente los esclavos, siendo su número superior al de blancos en relación de 20 a 1, un 80 por ciento de ellos trabajaba en las plantaciones.

A partir de 1751 y por casi una década, un africano cimarrón de nombre Mackandal, después de perder un brazo en un ingenio azucarero, se ocultó en los montes, desde donde atacaba las plantaciones, asesinando blancos e incitando a los esclavos a la insurgencia. Sus métodos de guerrilla fueron una gran influencia en los hechos que ocurrieron 
luego. En 1789 empieza la Revolución Francesa. La igualdad proclamada por la revolución no se aplicó a los esclavos, tampoco a los mulatos ni a los negros libres. Los terratenientes querían independencia y seguir manteniendo esclavos, como en Estados Unidos. Los blancos menores seguían fieles a Francia. En este país se creó la Sociedad de Amigos de los Negros. Su influencia causó recelo entre los terratenientes y acrecentó las esperanzas de igualdad entre los mulatos y los negros.

En 1790 unos 350 mulatos exigieron en Port-auPrince igualdad de derechos para mulatos y negros. La manifestación terminó con ejecuciones. Sus jefes escaparon al sector español de Santo Domingo, pero fueron entregados por los españoles y terminaron en el cadalso. En Francia continental, horrorizados por estos hechos, otorgaron la ciudadanía a un número pequeño de mulatos ricos, esto complicó la situación porque no alegró a los blancos ni a los mulatos. Creció la animadversión entre los pequeños blancos y los blancos ricos de la isla que buscaban la independencia. En 1791 empezó la rebelión. Liderados por el sacerdote vudú Boukman, miles de esclavos se sublevaron matando a todos los blancos y quemando las haciendas. Boukman fue muerto, pero los líderes continuarían luchando.

En 1792 la Asamblea Nacional de Francia dio la ciudadanía a los hombres libres de color. Para aplicar el decreto se envió una fuerza de 6.000 hombres al mando de Sonthonax. La medida no fue del agrado de los blancos y se rebelaron. La fuerza enviada recurrió a los mulatos, con estos y las tropas leales controlaron a blancos y a esclavos. Pero en 1793 Francia declaró la guerra a Inglaterra y el rey Luis XVI fue ajusticiado, iniciándose la República. Esto tiene consecuencias en Haití. Los realistas se alzaron en armas. Para derrotarlos Sonthonax recurrió a los mulatos y cerca de 10.000 esclavos a quienes dio la libertad. Derrotó a los realistas, pero la libertad de tantos esclavos molestó a los mulatos, que también tenían esclavos. Sin su principal apoyo y ante el peligro de invasión de los ingleses, buscó la ayuda de los negros decretando la emancipación general de los esclavos. En 1794 la Convención Nacional declara abolida la esclavitud en las colonias francesas (Coupeau, 2008).

Inglaterra y España vieron en la rica colonia de Saint Domingue una oportunidad de obtener una gran ganancia, para lo que invadieron Haití, pero fueron expulsados por las fuerzas haitianas que les opusieron un ejército de 51.000 soldados negros.
Expedición francesa. Napoleón quiso formar un gran imperio colonial en América haciéndose ceder la Luisiana, de España. Pensaba recuperar el control de su principal colonia: Saint Domingue, para lo cual envió una fuerte expedición militar de 24.000 hombres, en 1802. La lideraba el cuñado de Napoleón, el general de brigada Charles-VictorEmmanuel Leclerc (Roloff, 1990). Llegó a Haití logrando en primera instancia el acatamiento de una parte de sus habitantes, usando promesas falsas de no reinstaurar la esclavitud y respetar los grados militares de los oficiales haitianos. La otra parte de los habitantes no se dejó engañar. Se replegaron hacia el interior a posiciones más seguras, a la vez que seguían la táctica de tierra quemada. Los rebeldes firmaron un pacto de amistad con Inglaterra. Incendiaron Le Cap ante los invasores. Igual hicieron con otras ciudades como Port-de-Paix, Saint-Marc y Gonaïves. La lucha se generalizó contra el ejército invasor ya reducido en número y luego de una serie de campañas, el 18 de noviembre de 1803 fue la decisiva victoria haitiana en la Batalla de Vertierres, que forzó a las tropas francesas a la capitulación, poniendo término a la guerra de independencia ("Haiti", Encyclopedia Britannica, 2011).

Haití fue la segunda colonia americana en independizarse y la primera república negra del mundo. Derrotó a las tropas napoleónicas en plena expansión de ese imperio. Sus jefes demostraron una gran capacidad para planear, aplicando el uso racional del terreno, la artillería, entrenando y abasteciendo bien a sus tropas. Se destaca que sus comunicaciones fueron superiores a las de los europeos, la transmisión de mensajes se hacía por medio de señales de tambores, que los franceses no comprendían. Gracias a este sistema de comunicación, en todo momento los jefes haitianos estaban al corriente de los movimientos de las tropas enemigas, así como de sus buques de guerra cercanos a la costa. Las distintas unidades del ejército insurrecto recibían instrucciones por este medio, para atacar en el momento oportuno en los lugares elegidos, o retirarse disciplinadamente si la situación lo requería (Bourne, 1967). Se destaca que la artillería $\mathrm{y}$ armas de los rebeldes fueron suministradas por Estados Unidos e Inglaterra, pagadas con barriles de ron. La fiebre amarilla o paludismo también tuvo influencia en la debacle francesa, al final sus tropas acorraladas en una ciudad portuaria fueron presa de los mosquitos, en cambio los negros y mulatos tenían defensas contra esta enfermedad 
(Peterson, 1995). Esta derrota dejó un sabor amargo que Francia nunca perdonó.

\section{Consecuencias económicas y tecnológicas}

Después de la catástrofe social y económica que significó la derrota y retirada de los franceses de Haití, a instancias de Napoleón Bonaparte, científicos franceses analizaron muchas plantas buscando alguna que sustituyera la caña de azúcar. Se dio prioridad a la uva y la remolacha, debido a su alto contenido de azúcar. Finalmente el mayor esfuerzo fue dirigido a la remolacha, que ya en 1705 el francés Olivier Serrés había analizado con éxito. También en 1799 los alemanes la habían industrializado y producido en cantidad, pero debido a diversas razones no continuaron. En 1806 el Estado de Francia ofreció apoyo económico para producir azúcar de remolacha. En 1811 el Emperador dio la orden de explotar 32.875 hectáreas de remolacha. Se construyeron unas 40 fábricas en Francia, pero solo una sobrevivió a la guerra; sin embargo, la industria siguió creciendo, sobre todo en Alemania. Finalmente, a mediados del siglo XIX esta industria se estableció definitivamente en muchos países europeos.

Hubo un gran progreso en la eficiencia. En 1882 se necesitaban 18 kilos de remolacha para fabricar un kilo de azúcar; ya en 1886 se requerían 10 kilos; en 1904 menos de 7 kilos producían uno de azúcar. Estos grandes rendimientos han ido creciendo con el tiempo, debido a que los investigadores han mejorado la capacidad azucarera de la remolacha. De las plantas se han ido conservando únicamente los mejores ejemplares para producir semillas en el año siguiente y el método se aplicó generación tras generación, siempre manteniendo la calidad superior. Esta selección sistemática ha aumentado el contenido de azúcar de las remolachas. También se han superado los métodos de extracción del azúcar. Todos estos avances han permitido crear grandes industrias agrícolas en zonas templadas. Como en todos los procesos, el perfeccionamiento aún no termina.

\section{Agricultura intensiva}

Los cultivos de remolacha azucarera corresponden a una industria agrícola intensiva. Pueden realizarse de preferencia en suelo franco, blando y rico en minerales, ni muy arcilloso ni muy arenisco. Debe ser laboreado cuidadosamente y arado en profundidad. En Chile se emplean con éxito suelos rojos arcillosos y trumaos. El cuidado del cultivo fue en el pasado lo más laborioso, actualmente la mecanización de la agricultura ha aliviado esas labores. La plántula es pequeña y delicada, sólo niños y mujeres van a desmalezarla en los campos, aun en EE.UU. Hasta hoy no existe invención de equipos mecánicos que reemplacen el trabajo manual, aunque ayudan mucho los productos químicos para erradicar malezas. Una vez que los cultivos han sido establecidos, se realizan muchas labores. Al término del otoño las raíces se extraen fuera del terreno mediante arado y se le quitan las coronas. Luego se apilan las raíces y se transportan a las fábricas. Una industria de azúcar de remolacha es económica siempre que sea grande, a fin de procesar en forma continua las toneladas de materia prima que recibe. Hace 30 años los rendimientos medios en la VII Región de Chile eran de 50 toneladas métricas por hectárea. Usualmente se establece un poder comprador para adquirirlas de los pequeños y medianos productores, a quienes se suministran asesoría técnica, semillas, fertilizantes y pesticidas. Las remolachas son lavadas y luego trituradas; el azúcar se extrae de ellas mediante agua caliente, para luego cristalizarla a través de un secado. En seguida va a refino, donde se le da su color blanco definitivo, mediante productos químicos. Los subproductos tienen diversos usos: las hojas y tallos se emplean para alimento de animales, la pulpa de donde se extrajo el azúcar también se emplea para engorda de ganado (Llorente, 1998).

\section{Influencia del clima}

La remolacha crece en una zona muy amplia, desde regiones tropicales hasta cerca del Ártico. Sin embargo, las exigencias climáticas en la producción de remolacha azucarera son una balanceada cantidad de lluvias, un verano de calor moderado, no muy caluroso, y un otoño fresco. El maíz y la remolacha no compiten entre sí, por lo que se pueden hacer rotaciones de estos cultivos. En Europa se cultiva remolacha azucarera en la gran llanura que se va desde Normandía a la Rusia Central. Hay importantes cultivos en Alemania (que es la principal productora), Bélgica, Rusia, Francia, Holanda, España, Suecia y Dinamarca meridionales.

\section{Conflictos generados por el azúcar}

España heredó de Haití el cultivo de caña del azúcar en Cuba y Filipinas. Exportaba azúcar a Europa 
y mantenía un buen negocio que le generaba riquezas. En 1898 estalló la guerra hispano-norteamericana, debido al hundimiento del buque blindado Maine, en la bahía de La Habana, Cuba. Estados Unidos culpó a los españoles, imponiendo un ultimátum tan duro que fue inaceptable para éstos (Palma et al., 1969). Posteriormente se aclaró que se produjo un incendio espontáneo del carbón en los depósitos vecinos a la santabárbara del barco, lo que generó una gran explosión que hundió al acorazado. Buzos españoles determinaron que las planchas del Maine estaban deformadas hacia afuera del casco, lo que demostraba una explosión interna; sin embargo, los estadounidenses insistían en que fue una mina puesta a propósito. Como consecuencia, vino el enfrentamiento y la derrota española (Weiler, 1911). Pasaron a control de EE.UU. Cuba, Puerto Rico y Filipinas, como Hawai era un punto de abastecimiento marítimo en la ruta a Filipinas, también fue anexado. Existían excusas como la independencia cubana, pero el tiempo demostró que había también importantes intereses económicos: Estados Unidos se retiró de Cuba hasta bien entrado el siglo XX y de Filipinas al término de la II Guerra Mundial. A inicios del siglo XX, EE.UU. invadió Haití y República Dominicana, las que fueron ocupadas largos años (Schmidt, 1971).

A fines del siglo XIX, un potencial conflicto fue generado por la formación de trusts llevada a cabo por los industriales azucareros de Alemania y otros países. Estos trusts elevaron el precio en sus naciones, obteniendo grandes ganancias. Luego vendían el remanente en el extranjero a bajos precios. Así los gobiernos de Alemania, Francia, el Imperio Austro-Húngaro, Holanda, Bélgica y Rusia pagaban en parte el azúcar que exportaban. Fue para esos gobiernos un mal negocio del que se aprovecharon las dos grandes naciones importadoras: Estados Unidos e Inglaterra. Estas subvenciones incentivaron la producción en Europa acumulándose sobrantes de azúcar de remolacha (lo que acrecentaba los beneficios de los trusts). La competencia con el de caña fue tal, que Jamaica, las otras islas de la India Occidental y Guayana tuvieron una depresión por la baja en el precio. A fin de proteger la economía de sus colonias, Gran Bretaña amenazó gravar con un impuesto al azúcar importado. Cifra que fuese igual a la subvención que hubiera recibido en el país exportador, lo que habría beneficiado al tesoro inglés a expensa de los erarios de los productores europeos. Para buscar salida a la crisis debió celebrarse la Convención de Bruselas entre 1901 y 1902. Allí las naciones europeas acordaron suspender las concesiones a las exportaciones. Como resultado, el comercio mundial del azúcar fue regularizado.

Como efectos secundarios del dominio sobre territorios azucareros, en la Segunda Guerra Mundial la presencia militar norteamericana en Filipinas y Hawai fue, entre otras, una de las razones del ataque japonés a EE.UU., conflicto que terminó con dos bombardeos atómicos sobre Japón. Luego al inicio de los años sesenta, las mayores potencias del globo, la Unión Soviética y Estados Unidos, estuvieron a punto de iniciar una guerra nuclear por la presencia de misiles en Cuba.

\section{Proyecciones futuras de las plantas de azúcar}

El agotamiento de las reservas de hidrocarburos en el mundo; las frecuentes crisis políticas en los países productores; el calentamiento del planeta debido al crecimiento de la capa de $\mathrm{CO}_{2}$, así como el aumento en el precio del petróleo, han llevado al desarrollo de plantas generadoras de combustibles provenientes de la industria agrícola para producir otras fuentes de energía (Fernández, 1991). Es así como algunos países como Brasil ya cuentan con plantas de alcohol para combustible automotriz. Dadas las dificultades cada vez mayores de adquirir petróleo, es razonable suponer que estas industrias darían solución a este grave problema que se avecina (Inslee et al., 2007). Actualmente la producción de azúcar de caña ha tenido un gran avance, optimizándose los procesos (Chen et al., 1993) y dando un paso hacia la producción de bioetanol.

\section{Conclusiones}

El negocio de la caña de azúcar fue causante del malvado tráfico de esclavos africanos. La historia estaría incompleta sin una comprensión de la esclavitud africana, y como consecuencia la independencia de Saint Domingue, actual Haití.

Debido al impulso que dio Napoleón al desarrollo de la industria de la remolacha, hubo independencia económica de los centros de producción tropicales.

El azúcar tuvo gran incidencia en la Revolución Industrial, el mercado mundial y la creación del capitalismo del siglo XIX. 
Las políticas tarifarias influyeron en las guerras azucareras y la anexión hecha por Estados Unidos de Cuba, Puerto Rico, Hawai, Filipinas y en el dominio prolongado de Cuba y Santo Domingo.

Hubo serios efectos debido al control sobre antiguos territorios estratégicos que ya no tenían la importancia azucarera del pasado: ataque de Japón a Hawai y Filipinas en la II Guerra Mundial y la Crisis de los Misiles en Cuba.

Hubo una enorme expansión mundial del mercado. Cuba tuvo un brusco lanzamiento al mercado mundial, reemplazando a Haití como potencia productora.
Actualmente el azúcar es un alimento común en la dieta humana de todos los países, siendo considerado uno de los principales aportes energéticos para el hombre.

Se generó una cultura que abarcó todo el planeta, por ella se crearon tecnología, costumbres, historia, negocios, conflictos y se formó un puente que fue más allá de lo económico.

El consumo del azúcar entre los habitantes de las zonas templadas y frías es reciente, de alimento sofisticado se convirtió con el tiempo en alimento habitual.

\section{Literatura Citada}

Bourne, P.

1967 Los tambores del destino. Ed. G.P. Barcelona. $1^{\text {a }}$ ed. 533 p.

Coupeau, S.

2008 The History of Haiti. Westport, CT: Greenwood Press. $200 \mathrm{p}$.

Chen, J.C.P. y Chou, C.C.

1993 Cane Sugar Handbook. A Manual For Cane Sugar Manufacturers and Their Chemists. ISBN: 0-471-53037-9, 12a. edición, John Wiley \& Sons, Nueva York. 1090 p.

Espinoza, M.

1980 Zafra de odios, azúcar amargo. México: BUAP, pp. 2-15.

Fernández-Cavada, J.L.

1991 Optimización de la conversión de biomasa en alcohol, en AGROENERGETICA (Coord.). Ministerio Agr., Pesca y Alim. y CICYT, Madrid, pp. 465-493.

"Haiti", Encyclopedia Britannica, Online, Encyclopedia Britannica

2011 http://www.britannica.com/EBchecked/topic/251961/ Haiti.

Inslee, J. y Bracken, H.

2007 Apollo's Fire, Island Press, Washington, D.C., pp. 153155, 160-161, ISBN 978-1-59726-175-3.
Palma, E. y Weiler, V.

1969 La guerra de la independencia cubana. Extracto de Reportaje de la Historia. Tomo III.14 $4^{\mathrm{a}}$ edición. Ed. Planeta, pp. 69-75.

Peterson, R.K.D.

1995 Insects, disease, and military history: the Napoleonic campaigns and historical perception. American Entomologist. 41: $147-160$.

Roloff, G.

1990 Napoleon's Secret Instructions to General Leclerc. Munchen und Leipliz: Drud und Berlag von R. Oldenbourg, 1899.The "Anlagen", pp. 244-257. Department of Foreign Language, Webster University, August Edited by Bob Corbett, April 2003.

Schmidt, H.

1971 United States Occupation of Haiti, 1915-1934. New Brunswick, NJ: Rutgers UP., pp. 2-183.

Weiler, V.

1911 Mi mando en Cuba (La guerra de independencia cubana). Madrid, pp. 1-23. 